\title{
Gestão de pessoas em eventos de casamentos
}

\author{
People management in wedding events \\ Gestión de personas en eventos de bodas
}

Recebido: 08/06/2021 | Revisado: 16/06/2021 | Aceito: 21/06/2021 | Publicado: 06/07/2021

\author{
Luíse Gabrielle da Silva Batista \\ ORCID: https://orcid.org/0000-0002-2023-7377 \\ Instituto de Ensino Superior da Região Serrana ltda, Brasil \\ E-mail: luise-gabrielle@hotmail.com
}

\begin{abstract}
Resumo
Este artigo tem como objetivo mostrar a gestão de pessoas como ferramenta importante para o sucesso de um evento como o casamento serão mostrados os mecanismos necessários para que tal comemoração ocorra de forma satisfatória, desde o planejamento até a execução, tendo como principal elo a Assessoria de casamento para perfeita condução da solenidade. Aliado a dados estatísticos e ao passo a passo para realização do evento, tal como a junção de qualidade e satisfação, mostrando recursos, ações e estudos. Com ênfase na preparação das pessoas que fazem o evento acontecer, sabendo lidar com imprevistos, contornando-os ou realizando possíveis adaptações, de forma que fique imperceptível aos olhos dos clientes e convidados, colaborando assim para o sucesso da festividade. Verificou-se através de pesquisas que o número de casamentos e festas reduziu, devido a fatores externos, mesmo casais que já planejavam tiveram seus sonhos adiados, exigindo que o cuidado com a prestação de serviços seja ainda maior, pois estão lidando com sentimentos, sonhos e ansiedade. O conhecimento prévio em administração será necessário para o andamento da empresa, dentro disso a liderança e marketing serão essenciais, sempre priorizando a ética e a transparência.
\end{abstract}

Palavras-chave: Assessoria; Casamento; Planejamento; Gestão de pessoas; Liderança.

\begin{abstract}
This article aims to show people management as an important tool for the success of an event such as a wedding, the necessary mechanisms will be shown for such a celebration to occur satisfactorily, from planning to execution, with the main link to the Assessoria de marriage for the perfect conduct of the solemnity. Allied to statistical data and step by step for the event, such as the combination of quality and satisfaction, showing resources, actions and studies. With an emphasis on preparing the people who make the event happen, knowing how to deal with unforeseen events, bypassing them or making possible adaptations, in a way that is imperceptible to the eyes of customers and guests, thus contributing to the success of the festival. It was found through research that the number of weddings and parties reduced, due to external factors, even couples who were already planning had their dreams postponed, demanding that the care with the provision of services be even greater, as they are dealing with feelings, dreams and anxiety. Prior knowledge in administration will be necessary for the company's progress, within that leadership and marketing will be essential, always prioritizing ethics and transparency.
\end{abstract}

Keywords: Advice; Wedding; Planning; People management; Leadership.

\section{Resumen}

Este artículo tiene como objetivo mostrar la gestión de personas como una herramienta importante para el éxito de un evento como una boda, se mostrarán los mecanismos necesarios para que dicha celebración se produzca de forma satisfactoria, desde la planificación hasta la ejecución, con el enlace principal a la Assessoria de Matrimonio. por la perfecta conducción de la solemnidad. Aliado a datos estadísticos y paso a paso para el evento, como la combinación de calidad y satisfacción, mostrando recursos, acciones y estudios. Con énfasis en preparar a las personas que hacen que el evento suceda, sabiendo lidiar con imprevistos, evitándolos o haciendo posibles adaptaciones, para que sea imperceptible a los ojos de clientes e invitados, contribuyendo así al éxito del festival. Se encontró a través de la investigación que se redujo el número de bodas y fiestas, debido a factores externos, incluso las parejas que ya estaban planificando sus sueños se pospusieron, exigiendo que el cuidado con la prestación de servicios sea aún mayor, ya que se trata de sentimientos, sueños y ansiedad. Los conocimientos previos en administración serán necesarios para el progreso de la empresa, dentro de los cuales el liderazgo y el marketing serán fundamentales, priorizando siempre la ética y la transparencia.

Palabras clave: Asesoramiento; Boda; Planificación; Gestión de personas; Liderazgo. 


\section{Introdução}

Em 2020 os números de casamento foram bem menores devido à pandemia, com diversos estabelecimentos fechados, houve muitas remarcações e cancelamentos, fornecedores da área ficaram sem renda e tiveram que realizar várias manobras para se levantar diante da crise. No segundo semestre do mesmo ano foi autorizada a reabertura de salões e espaços para realização de eventos no Rio de Janeiro, muitos casamentos que haviam sido adiados voltaram a acontecer (Saraiva, 2020).

Esse dia é tão especial para os noivos, são meses e às vezes anos de preparo e cuidado para realização desse sonho, se não houver um bom planejamento e uma equipe preparada tudo se torna uma frustração. Tendo uma equipe bem treinada e disposta reduz-se qualquer probabilidade de erros antes ou durante o evento.

As famílias estão adequando seus sonhos a suas realidades econômicas diante da crise, com uma boa gestão de pessoas consegue-se agregar valor aos serviços prestados, com o objetivo maior de transformar sonhos em eventos bemsucedidos e inesquecíveis.

Os noivos sempre estão muito emocionados e envolvidos com outras questões durante a festa ou cerimônia, muitas vezes não conseguem perceber detalhes que impedem que tudo transcorra bem.

É possível realizar eventos ideais sabendo gerir os colaboradores com motivação, comunicação e trabalho em equipe, unindo habilidades e competências de cada um, trazendo aos funcionários capacitação, levando ao crescimento da equipe, que são os pilares da Gestão de Pessoas (Vicente, 2021).

Através de pesquisas bibliográficas e experiências pessoais será mostrado nesse artigo medidas para garantir a tranquilidade do casal, juntamente com a Assessoria responsável pela organização, realizando reuniões pré-evento para garantir o entendimento e a realização de tudo que foi contratado, preparando as equipes para o atendimento ideal no dia do evento, fazendo um checklist e prevendo possíveis contratempos.

\section{Metodologia}

O presente artigo utilizou pesquisas bibliográficas, exploratórias e qualitativas, baseado nessas pesquisas e nos conhecimentos pessoais existentes foi possível elaborar este trabalho científico, buscando fontes seguras e confiáveis, capazes de mostrar elementos necessários para elaboração de projeto de pesquisa e organização de conhecimentos dispersos ao longo da vida acadêmica (Bêrni \& Fernandez, 2009, Barney \& Hesterly, 2011, Gil, 2017). A pesquisa foi realizada durante o primeiro semestre do presente ano de 2021. Além disso, foram vistos alguns artigos como referência conforme: Carvalho \& Oliveira, Moura \& Morais, 2016). A importância da gestão de pessoas em eventos: um estudo comparativo entre a visão de clientes e a da administração de um bufê (Bueno \& Gama, 2021). A atuação dos gestores que trabalham em espaços socioeducativos na pandemia Cuque et al. (2021).

\section{Resultados e Discussão}

Segundo Chiavenato (2009), a área de RH representa a maneira como as organizações procuram lidar com as pessoas que trabalham em conjunto em plena era da informação. Não mais como recursos organizacionais que precisam ser passivamente administrados, mas como seres inteligentes e proativos, capazes de responsabilidade e iniciativa e dotados de habilidades e conhecimentos que ajudam a administrar os demais recursos organizacionais inertes e sem vida.

As pessoas constituem o principal ativo das organizações. Daí a necessidade de tornar as organizações mais conscientes e atentas a seus funcionários. As organizações bem-sucedidas percebendo que somente podem crescer, prosperar e manter sua continuidade se forem capazes de otimizar o retorno sobre os investimentos de todos os parceiros principalmente o dos empregados (Chiavenato, 1999). 
$\mathrm{O}$ investimento em equipes tem o potencial de fazer com que profissionais trabalhem mais satisfeitos e engajados, produzindo melhores resultados para a companhia, para isso, é necessário que os envolvidos na gestão estejam em sintonia com as equipes e identifiquem os perfis mais adaptados à cultura para focar em ações de engajamento, envolvimento e motivação dos mesmos, ações estas que devem estar alinhadas com o planejamento estratégico da empresa.

Essas técnicas podem ser usadas em empresas de todos os portes, a organização cresce e seus colaboradores também, quando se tem o conhecimento necessário para gerir e capacitá-los, e a qualidade dos serviços prestados são vistos por todos.

De acordo com Guimarães (2021), os objetivos da gestão estratégica de pessoas envolvem:

- Apoiar a organização no alcance de suas metas, desenvolvendo e implementando ações dos recursos humanos, integradas com a estratégia de negócios;

- Contribuir para o desenvolvimento de uma cultura de alto desempenho;

- Garantir que a organização tenha as pessoas talentosas, qualificadas e engajadas que precisa;

- Criar uma relação de emprego positiva entre a gerência e os funcionários e um clima de confiança mútua;

- Incentivar a aplicação de uma abordagem ética à gestão de pessoas (Guimarães, 2021).

Nesse contexto, a gestão de pessoas e dos recursos humanos acabou ganhando bastante força nos últimos tempos. Atualmente, administrar os recursos humanos e potencializar o desempenho de quem faz parte de uma empresa virou um grande diferencial competitivo, e esse potencial competitivo faz toda diferença nesse universo atual, as empresas devem se apoiar em técnicas sólidas para não chegarem a decretar falência. Por isso, fazer a gestão de recursos humanos não se trata apenas de procurar deixar seus colaboradores satisfeitos e motivados, mas de criar uma estratégia completa, que engloba toda organização em busca do desenvolvimento, capacitação e humanização de quem faz parte dela. A Figura 1 ilustra os 5 pilares da gestão de pessoas.

Figura 1. 5 pilares essenciais da gestão de pessoas:

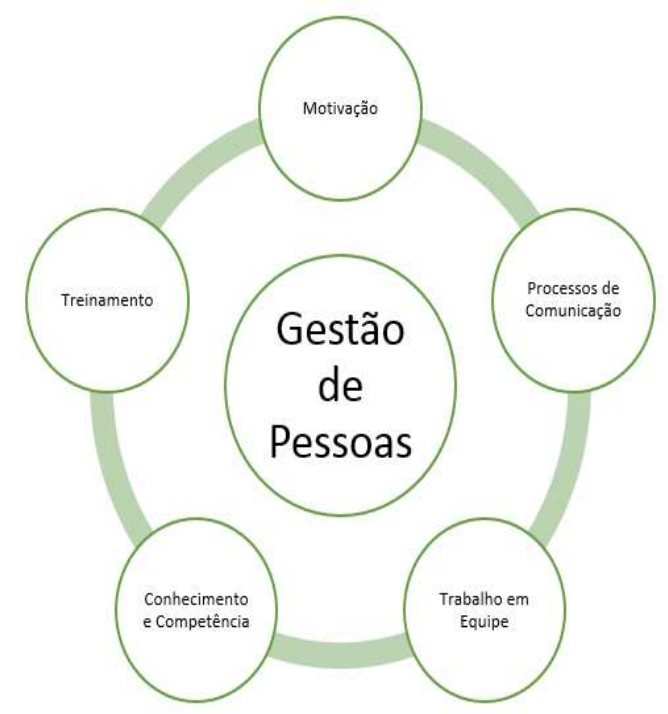

Fonte: Avila (2015).

Recursos humanos e Gestão de pessoas possuem definições diferentes, mas se complementam, os profissionais do RH devem estar sempre atentos aos acontecimentos, tendências e inovações do mercado em se tratando de gestão de pessoas para dar suporte na hora de realizar os processos de recrutamento e seleção (Figura 2). 
Figura 2. RH x Gestão de pessoas.

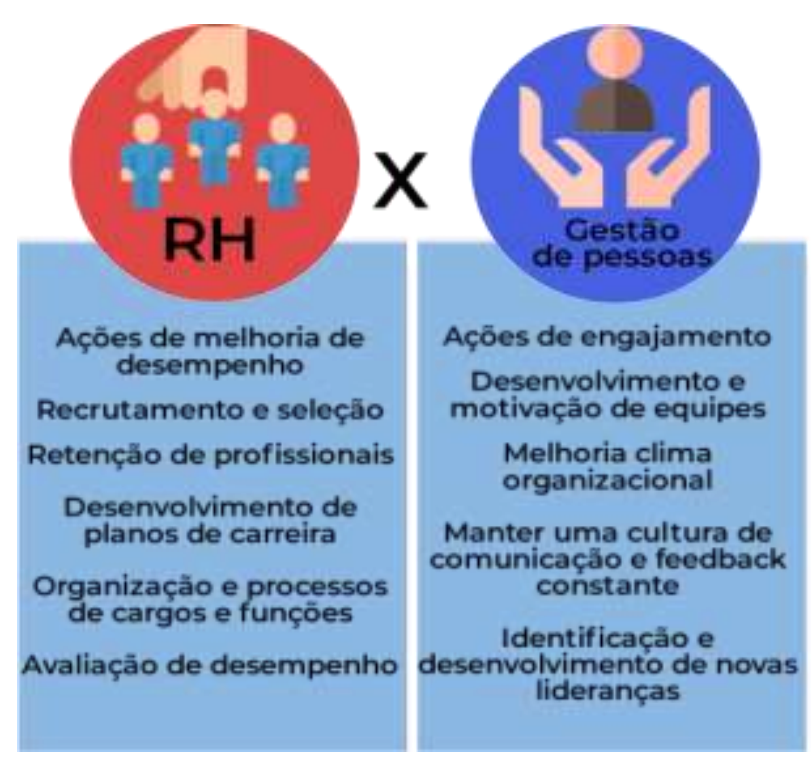

Fonte: Guimarães (2021).

A empresa que deseja alcançar vantagem competitiva precisa se adaptar ao comportamento dos profissionais que agora utilizam as plataformas virtuais, os portais de vagas e as redes sociais como ambiente de interação, busca de oportunidades e busca de serviços.

É papel do marketing nas empresas definir os objetivos junto aos clientes bem como a maneira ideal de satisfazer necessidades e desejos, de forma lucrativa e competitiva. Identifica-se uma oferta considerável de empresas que visam satisfazer estas necessidades, sendo assim, uma empresa para sobreviver não pode unicamente realizar um ótimo trabalho. A palavra ideal no momento que melhor define a possibilidade de sobrevivência é a excelência. Isto garantirá a perenidade da empresa (Silva \& Minciotti, 2021).

Vale ressaltar também a importância da liderança para o pleno funcionamento dos processos organizacionais, pois lideres eficientes influenciam pessoas positivamente alcançando os objetivos da empresa, além de saber responder de forma diferenciada diante de cada situação.

"Liderança: o novo imperativo é o desenvolvimento da liderança nas organizações. A identificação e o desenvolvimento de pessoas excepcionais capazes de levar as organizações para o novo século será fundamental. A criação de lideres de lideres será vital. E o segredo do sucesso estará cada vez mais nas pessoas." (Chiavenato, 2009, p.409).

Um dos maiores desafios ao produzir eventos é uma gestão de pessoas que realmente funciona, ou seja, que o trabalho de cada colaborador flua bem e como o esperado até o término do evento. E esse é um desafio para eventos de todos os tamanhos! Quanto maior o evento, mais pessoas para gerenciar e liderar. Mas as necessidades básicas de uma gestão de pessoas eficientes de equipes durante eventos são a mesma tanto para cinco colaboradores quanto para trezentos. (Carboniere, 2019).

\subsection{Assessoria}

Para que um evento como a festa de casamento ocorra bem e sem muitas preocupações pela parte dos noivos, é necessária uma assessoria que é responsável por cuidar de todos os detalhes, desde a idealização do evento até a realização do mesmo, coordenando todo o cerimonial e orientando toda à equipe profissional de acordo com o protocolo, assim como um bom bufê que tem a função de comprar todas as comidas e bebidas que serão servidas, além de coordenar a equipe de garçons para que sirvam bem aos convidados. É necessário também um bom espaço que seja de acordo com a necessidade da família 
que realizará o evento. Os contratantes também têm a opção de obter um pacote, com tudo isso e mais outros detalhes, como fotografia, filmagem, convites, buquê, viagem de lua de mel, carro, etc.

Assessoria, que consiste na organização e coordenação geral do evento, para garantir a qualidade dos serviços prestados e coordenar a equipe profissional atuante no evento para que tudo ocorra conforme o planejado, o serviço vai além da prévia da organização do evento em si, pois também tem a responsabilidade após o evento, tudo isso, claro, pensado para facilitar a vida dos noivos. Com o desejo que eles e seus familiares possam entregar toda a responsabilidade pelo evento a pessoas preparadas e possam curtir verdadeiramente, esse dia de forma inesquecível.

Sendo da forma que o casal desejar, contratando uma assessoria ela estabelecerá parcerias com os melhores fornecedores do mercado e profissionais altamente capacitados que possuam experiência com esse tipo de serviço, em busca dos melhores preços, descontos e condições de pagamento mais acessível para os noivos, ofertando um orçamento que esteja de acordo com a realidade social de cada um. Sabemos que os detalhes que envolvem esse tipo de evento são inúmeros e para que nenhum detalhe passe despercebido eles montarão um cronograma para estabelecer as prioridades.

Um casamento sem norte é percebido nitidamente pelos convidados, hoje em dia para realizar um evento desse porte é essencial um suporte profissional para que ninguém fique sobrecarregado e possam aproveitar esse momento tão especial, por isso a assessoria em um casamento deixou de ser um luxo e se tornou peça chave no planejamento do evento, ela será responsável pela gestão das pessoas e da matéria prima juntamente com os profissionais responsáveis.

A falta de uma assessoria, responsável por inúmeros detalhes que englobam uma cerimônia, ocasiona a preocupação dos noivos e seus parentes em diversos momentos do evento, para que os convidados e os noivos possam aproveitar da melhor maneira possível esse dia, a equipe de assessoria deverá estar pronta para solucionar qualquer tipo de emergência e imprevistos que possam ocorrer durante a realização do evento.

Para a comodidade dos clientes, podem-se ofertar diversos tipos de serviços, assessoria do dia com cerimonial, assessoria parcial, assessoria completa e a mais nova com transmissão de evento virtual, sendo assim com realidade aumentada, a empresa cuida de todos os detalhes junto ao cliente e transmite o evento online.

Conforme mostra Lima (2021), há diversas opções de eventos online, de forma a criar um ambiente virtual de grande interatividade. Mostram opções para diversos tipos de eventos, que tem sido uma alternativa para as empresas atualmente

\subsection{Equipe}

As experiências e competências que o profissional traz, têm grande importância no desempenho de seu trabalho, podendo ser aplicada ao longo de sua carreira, independente da função que ele esteja exercendo.

Uma equipe bem treinada e de sucesso torna-se cada vez mais conhecida, muito mais do que a internet a propaganda boca a boca é essencial, profissionais que mergulham nos projetos dos seus clientes, que auxiliam na realização de sonhos, ofertam comodidade e qualidade nos serviços prestados. Quando seu estabelecimento faz o cliente economizar tempo, dinheiro e obter satisfação, consequentemente se traz orgulho, e agrega valor ao seu empreendimento.

Um bom grupo de trabalho identifica o perfil dos noivos e realiza uma parceria com eles para que seus sonhos tornem-se realidade e o evento tenha realmente a "cara" dos noivos em todos os detalhes deve-se haver essa empatia do grupo de trabalho com os clientes.

Para Wood Junior, T. \& Zuffo, P. K. (1998), no novo cenário competitivo, muitas vezes a empresa se confunde com o ambiente, misturando-se om fornecedores e clientes. Fica difícil saber onde termina a cooperação e começa a concorrência.

Para apresentar aos clientes uma maior diversificação de serviços, empresas de assessoria devem oferecer tipos diferentes de pacotes que podem ser alinhados aos desejos e a realidade financeira dos noivos. Deve ser feita uma pesquisa de 
mercado assim será possível realizar o plano de negócios, bem como seu planejamento estratégico, plano operacional, plano de marketing e sua viabilidade financeira.

"Uma empresa com vantagem competitiva quando cria mais valor econômico do que suas rivais, e valor econômico é a diferença entre benefícios percebidos pelo consumidor associados a compra de produtos ou serviços de uma empresa e o custo para produzir e vender esses produtos ou serviços.” (Barney, J. B. \& Hesterly, W. S., 2011, p.10)

A tarefa de organizar um casamento não é nada fácil, principalmente nos dias de hoje. Com a vida moderna, as pessoas estão muito empenhadas em suas profissões e os inúmeros detalhes existentes em uma cerimônia de casamento, acaba se tornando um processo muito estressante para os noivos.

A principal causa de eventos fracassados é a falta de planejamento e organização, tudo isso pode ser evitado quando se conhece o público a ser atingido, pois o que pode ser deslumbrante numa região pode ser cafona em outra, tudo isso se aplica desde a vestimenta dos colaboradores até as comidas a serem servidas aos convidados. Quando se faz um trabalho junto aos noivos desde o início com um bom planejamento é possível proporcionar qualidade e tranquilidade.

\subsection{A influência da situação econômica do país na realização de eventos}

A atual situação econômica brasileira é grave, a crise econômica deixou de ser uma hipótese para se tornar realidade, não apenas para os empregados, pessoas comuns que dependem de seus trabalhos, mas também para os empresários e empreendedores. Toda a população brasileira se encontra preocupada com os rumos que a economia brasileira vem se guiando nos últimos meses. Por conta da crise econômica que assola o país, os empresários estão adiando seus investimentos, principalmente os que necessitam de crédito para a manutenção do negócio e os empreendedores retardando seus projetos.

Um fator importante na crise instaurada no Brasil foi à falta de políticas econômicas voltadas para estimular a competitividade da economia brasileira.

No Brasil, dentre os problemas já existentes, os baixos investimentos em infraestrutura no país, os recentes escândalos de corrupção, o impeachment da ex-presidente Dilma Rousseff, os confrontos partidários e as altas taxas de juros fizeram com que o Brasil perdesse a credibilidade interna e externa.

Tivemos um ano atípico para o ramo de eventos, devido às regras de isolamento impostas pelo governo resultado da epidemia de corona vírus, com isso DJs não tiveram festas para realizar, salões de festas permaneceram fechados, bufês fechados, por um longo período, tudo isso gera uma rede de pessoas sem trabalho e sem renda. Durante esse período muitos trabalharam com entrega, festas em casa ou de outras formas para obtenção de renda, a partir do momento que foram liberados para continuar com tais festejos as empresas tiveram que se adaptar as novas regras, pesquisa realizada pelo SEBRAE mostra como a crise tem afetado o segmento.

\subsection{Pesquisa realizada pelo Serviço Brasileiro de Apoio às Micro e Pequenas Empresas (SEBRAE)}

O isolamento social é uma das medidas preventivas para conter a aglomeração de pessoas e, assim, evitar a proliferação do novo coronavírus. Com isso, o segmento de eventos do país sofreu drasticamente. Um levantamento feito pelo SEBRAE aponta, que em abril, a pandemia do coronavírus afetou 98\% do setor de eventos. Apesar de terem sido impactadas pela crise, $64 \%$ das empresas afirmam que não preveem demissão dos funcionários nos próximos três meses.

Para tentar amenizar os efeitos da crise, empresários tentam negociar prazos: 34\% devolveram o dinheiro para o contratante, mas $35 \%$ deles contam que conseguiram negociar crédito para utilizar futuramente.

A pesquisa ouviu prestadores de serviços de organização de feiras, congressos, exposições e festas, além de profissionais cujos trabalhos envolvem aluguel de estruturas como palcos, estandes, iluminação, som, bem como serviços de 
filmagens, produção fotográfica, bufê de festas, decoração, assessoria cerimonial, seguranças, transporte, agência e operadora de turismo, entre outros.

O impacto provocado pela Covid-19 também fica evidente observando o faturamento do setor. Em comparação ao mês de abril do ano passado, 62,5\% dos entrevistados acreditam na redução de 76\% a 100\% do faturamento em abril deste ano de 2020.

Estão sendo feitas adaptações para a sobrevivência dos negócios buscando soluções para sobreviver a este momento e visando à preparação para a retomada dos negócios, 30,1\% dos empresários estão aprimorando a gestão. Uma preocupação também é o relacionamento com o mercado: $25,2 \%$ dos entrevistados estão fortalecendo essa relação.

As medidas adotadas durante a quarentena para evitar a falência abrangem a capacitação de funcionários: 17,2\% dos empresários investem em qualificação da equipe para esse novo momento, e 15,5\% adotam o uso de novas tecnologias.

Para minimizar os impactos nesse setor é necessária a atuação conjunta das entidades de apoio do setor de negócios e eventos. Trabalhando junto é possível elaborar projetos e políticas assertivas para desenvolvimento do setor e recuperação da economia (SEBRAE, 2020).

\subsection{Ações necessárias}

Daí a importância da estratégia organizacional, ela representa a maneira pela qual a empresa se comporta frente ao ambiente que a circunda, procurando aproveitar as oportunidades do ambiente e neutralizar as ameaças potenciais que rondam os seus negócios. É uma questão de saber ajustar-se as situações. É um conjunto de manobras que se desenvolve em um ambiente competitivo: aproveitar as oportunidades externas e esquivar-se de ameaças ambientais ao mesmo tempo em que aplicam mais intensamente as forças internas e se corrigem as fraquezas internas. (Chiavenato, 1999. p. 56).

Para que tudo saia bem é necessário seguir um cronograma, a empresa passará esses detalhes junto aos noivos. Primeiramente devem alinhar que tipo de casamento pretende: civil, religioso, formal, semiformal ou informal (casual), na praia, num hotel, ou no jardim da casa da família. Marquem ou tentem marcar uma data para o dia do casamento; se vão casar na igreja, confirmem a data com o sacerdote ou pastor. Determinem o orçamento de que dispõem, e quem irá contribuir para ele. Criem um dossiê onde incluirão todos os detalhes relativos ao casamento: contatos de fornecedores, contratos, moradas, imagens. Iniciem a lista dos convidados, decidam quantas pessoas serão convidadas e comecem a desenvolver essa lista. Caso optem por um casamento Católico, informe-se sobre a paróquia onde pretendem realizar o casamento, quando e onde se dará o Curso de Preparação para o Matrimônio. Comecem a pesquisar um local para a recepção, de acordo com o orçamento e com o estilo do casamento. Pesquisar fornecedores de casamento, como florista, fotógrafo e vídeo, catering, designer do bolo de casamento e banda. Convidar os padrinhos e outros convidados que pretendam que ajudem no vosso casamento, e informemnos das datas relevantes.

De 9 a 11 meses antes devem visitar os locais selecionados para a recepção, e decidam o local final. Se vão ter uma cerimônia religiosa, marquem uma reunião com os responsáveis onde se realizará a celebração para decidirem todos os detalhes. Entre em contato com diversos serviços de catering e comecem a delinear o que desejam para a ementa. Reservem o fotógrafo e o comecem a pensar no tipo de álbum e de filme que desejam.

Marquem reuniões com floristas ou designers florais para decidirem quem vai fazer e como será a decoração do casamento. Pesquisem locais para a lua-de-mel. Comecem a procurar convites de casamento. Definindo a data, horário, localização, estilo e nível de formalidade do casamento, comecem a pesquisar o vestido de noiva e o traje do noivo.

De 6 a 8 meses antes devem marcar reuniões com a banda ou DJ e decidir quem vai atuar no casamento. Decidam que tipos de presentes gostariam de receber e façam as listas de casamento nas lojas que pretendem. Finalizem a lista de convidados. Marque a lua-de-mel, destinos populares durante a época alta poderão ter de ser marcados com muita 
antecedência. Se o local da recepção não tem materiais, como tenda, cadeiras, mesas ou talheres, o ideal será reservarem desde já todo o equipamento necessário. Determinem a decoração floral dos locais e deem as linhas orientadoras à florista. Façam algumas provas de comida e decidam-se por uma empresa de catering. Encomendem os convites. Façam uma consulta de rotina, marquem análises ao sangue e exames físicos que considerem pertinentes. Não se esqueçam de ver se necessitam de vacinas obrigatórias para viajarem para o local onde vão passar a lua-de-mel. Seis meses antes, devem dirigir-se à Registo Civil, dando assim início ao processo de casamento. Entreguem para impressão os convites ou mandem faze-los à mão, caso assim o desejem.

Com 3 a 4 meses de antecedência devem comprar as alianças, permitindo o tempo necessário para gravá-las, caso assim o desejem. Comecem a preparar com todos os fornecedores uma tabela de ocorrências.

Após isso devem terminar a lista de casamento e os lugares de todos os convidados. Decidam o bolo de casamento e façam a sua encomenda. Enderecem os convites de casamento e preparem-se para enviá-los. Planejem o ensaio do casamento, e combinem-no com o oficial de cerimônia. Marquem o alojamento para a noite de núpcias. Entrevistem músicos para a cerimônia, ou prepare as musicas Falem com as pessoas às quais gostariam de atribuir um papel especial na celebração. Comece a planejar o chá de panelas, passando a lista de pedidos e enviando convites Contratem o transporte necessário para o dia. Comprem as passagens de avião, hotel e transporte para a lua-de-mel. Façam a escolha final dos fornecedores do casamento, e assinem os contratos. Se não fazem exercício, esta é uma ótima ocasião para começar, pois nada como estar em forma no dia do casamento. Comprem os sapatos e todos os acessórios como lingerie e acessórios para o cabelo, joias, gravata..

Nas 4 a 6 semanas anteriores se já receberam presentes, podem começar a escrever notas de agradecimento. Componham, desenhem e imprimam os missais. Confirmem todos os contratos com os fornecedores que vão realizar o casamento. Façam as provas finais do vestido de noiva e traje do noivo. Façam as provas finais do cardápio da recepção. Façam as mudanças necessárias nas contas do banco caso o desejem, seguros, e outros documentos legais. Selecionem os presentes para oferecer um ao outro no dia do casamento. Confirmem o ensaio da cerimônia com o oficial, e toda a festa de casamento.

Caso desejem façam o chá de panela e as despedidas de solteiros. Comecem a preparar a disposição dos convidados, bem como todos os marcadores e cartões de escolta. Terminem a tabela de ocorrências e entreguem-na a todos os fornecedores e pessoas envolvidas.

Restando duas semanas reconfirmem todos os preparativos relativos ao casamento, telefonem aos convidados que não responderam ao convite, para saber se eles tencionam comparecer ou não. Finalizem o plano para posicionar os convidados durante a solenidade e durante a recepção. Confirmem os horários e locais com o fotógrafo, com o came Raman, DJ ou banda, e músicos da cerimônia. Façam um tratamento facial. Marquem uma consulta no dentista para fazerem uma limpeza de dentes. A noiva deve visitar o salão de beleza para um ensaio de maquiagem e penteado, experimentar o véu ou as peças que pretenda usar no cabelo. Deve aproveitar para fazer também uma estimativa do tempo necessário à maquiagem e penteado para programar a manhã do casamento. Vão buscar as alianças de casamento à joalharia. Voltem a reconfirmar todos os preparativos para a lua-de-mel.

Durante a semana comuniquem o número final de convidados à assessoria e ao local de recepção. O noivo deve fazer um corte de cabelo. Preparem as malas para a lua-de-mel. No dia anterior ao casamento confirmar o horário com a manicure. Pegar o vestido e traje do noivo na loja. Assim como os trajes das daminhas e dos pajens, levar todas as lembranças e outros adereços a Assessoria, Preparar o dinheiro e o cheque para os pagamentos no dia.

No dia a equipe responsável e os noivos se desejarem vão ao local da festa e/ou igreja para verificar a montagem do casamento e resolver todos os problemas que possam ocorrer, levar os brindes, buquê, anel e outros adereços ao local da cerimônia (Azevedo, 2009, Cerimonial, 2015). 
A empresa responsável também deve fazer um gerenciamento de riscos que está dividido em alguns processos: Planejamento do gerenciamento de riscos: Planejar as atividades de gerência de risco a serem realizadas para o projeto. Identificação de riscos: Determinação dos riscos que podem afetar o projeto e documentação de suas características. Todo problema identificado com antecedência tem $90 \%$ de chance de não acontecer. Análise qualitativa de riscos: Priorização dos riscos para análise ou ação adicional subsequente através de avaliação e combinação de sua probabilidade de ocorrência e impacto. Análise quantitativa de riscos: Analisa numericamente a probabilidade de um risco ocorrer e sua consequência para o projeto. Planejamento de resposta aos riscos: Desenvolve opções e determina ações para aumentar as oportunidades e reduzir as ameaças. (TRT, 2021).

Uma empresa sólida se preocupa também com a questão socioambiental e busca realizar parcerias com fornecedores que compartilham desse comprometimento.

Equipes de Assessoria devem ser para os clientes um referencial de qualidade e excelência, garantindo-lhes toda a assistência, segurança e confiança na realização do evento, sempre superando suas expectativas, conhecendo o mercado e tendo uma imagem forte e única junto aos clientes, fornecedores, colaboradores, comunidade e investidores.

Conforme Cavaco (2012), no atendimento ao público em particular a competência comportamental é a chave para o sucesso na hora de prestar um serviço onde irá lidar com diversos tipos de pessoas.

Para atingir o sucesso estratégico, as organizações de eventos devem possuir mão de obra qualificada, sendo necessário que se realizem boas práticas de recrutamento e seleção, treinamento e desenvolvimento e motivação.

\section{Considerações Finais}

Foi visto que a organização de um casamento não é uma ttarefa tão simples, pois tem inúmeros detalhes a serem lembrados, se os noivos tiverem uma equipe preparada e de confiança torna as coisas mais leves, com comunicação, tecnologia e unindo as ferramentas de gerenciamento de riscos, gestão de projetos e gestão de pessoas o evento está garantido, com toda qualidade.

O tema tratado no artigo é de extrema importância, uma boa gestão de pessoas, sabe agir diante de qualquer imprevisto que possa ocorrer, evitando gastos desnecessários passando assim despercebido pelos convidados. Ao contratar uma Assessoria, um bom Bufê você delega funções a pessoas de confiança, evita gastos desnecessários e preocupações além, pois sabem responder de forma rápida e eficaz em diversas situações, e assim os noivos e convidados podem curtir o dia com serenidade.

Foram apresentados, elementos, recursos e ações que são necessárias para um evento de sucesso. Uma boa empresa possui também um olhar para inclusão social, estimulando as habilidades de cada um. A empresa vai captar seus recursos e capital humano para agregar valor ao evento dos clientes, unindo uma boa gestão para aplicação em empresas que promovem desde grandes festas a cerimônias simples.

O sucesso vem de dentro para fora, com profissionais bem capacitados, motivados e com trabalho em equipe é possível formar uma empresa sólida e bem-sucedida, levando para seus clientes o que desejam e até mais do que imaginam, sendo assim é preciso colher informações junto ao contratante e oferecer o melhor de acordo com que cada um possa cumprir.

O ramo de eventos, seja o de casamentos ou outros, faz parte do dia a dia de todos na sociedade, seja no trabalho, escola ou vida pessoal, o estudo dessa temática permitirá que clientes ou empresas tenham direção e base para implementação. São diversos assuntos que podem ser abordados em trabalhos futuros, aos que desejarem poderão levar a fundo tópicos relacionados, como a importância do marketing para empresas de eventos, formas de eventos no contexto atual, economia e versatilidade e assim por diante. 
Research, Society and Development, v. 10, n. 8, e4810816963, 2021

(CC BY 4.0) | ISSN 2525-3409 | DOI: http://dx.doi.org/10.33448/rsd-v10i8.16963

\section{Referências}

Ávila, R. (2015). Os 5 pilares da Gestão de pessoas. Website blog luz. https://blog.luz.vc/o-que-e/os-5-pilares-da-gestao-de-pessoas/

Azevedo, P. R. (2009). Gestão do evento casamento utilizando técnicas de elaboração de projeto. Website AVM.

https://www.avm.edu.br/docpdf/monografias_publicadas/b001154.pdf

Barney, J. B. \& Hesterly, W. S.(2011). Administração e vantagem competitiva- conceitos e casos. (3 $3^{\mathrm{a}}$ ed.). Pearson.

Bêrni, D. A. \& Fernandez, B. P. M. (2009). Métodos e técnicas de pesquisa. Saraiva.

Bueno, E. C. \& Gama, M. E. R. (2021). A atuação dos gestores que trabalham em espaços socioeducativos na pandemia. Research, Society and Development. 10(4), e17110414012. DOI: 10.33448/rsd-v10i4.14012. https://rsdjournal.org/index.php/rsd/article/view/14012.

Carboniere, B. (2019). Gestão de pessoas em eventos. Website moblee. https://www.moblee.com.br/blog/gestao-de-pessoas-em-eventos/

Carvalho, A. B. \& Oliveira G. C. \& Moura, F. V. \& Morais G. M. D. (2016). A importância da gestão de pessoas em eventos: um estudo comparativo entre a visão de clientes e a da administração de um bufê. FTT Journal Of Engineering and Business. http://journal.ftt.com.br/seer/index.php/FTT/article/view/23.

Cavaco, N. A., (2012). Atendimento ao público nível avançado. Academia do Cérebro. IBRAPCHS.

Cerimonial, E. (2015). O jeito formal de organizar festas e eventos. Blogpost cerimonial Estellita. https://cerimonialestellita.blogspot.com/2015

Chiavenato, I.(1999). Gestão de Pessoa: O novo papel dos recursos humanos nas organizações. Atlas.

Chiavenato, I. (2009). Recursos Humanos: O capital humano das organizações. (9ª . ed.). Elsevier.

Cuque, L. et al. (2021). Design thinking e o desenvolvimento de competências dos profissionais do século XXI. Research, Society and Development. 10(5), e31210514949. DOI: 10.33448/rsd-v10i5.14949. https://rsdjournal.org/index.php/rsd/article/view/14949.

Gil, A. C. (2017). Como elaborar projetos de pesquisa. Atlas.

Guimarães, B. (2021). Gestão de pessoas: O que é, processos, objetivos e pilares. Website Gupy. https://www.gupy.io/blog/gestao-de-pessoas.

Kato, D. Y. \& Mello, E. (2016). Eventos sociais: A importância do planejamento para casamentos. https://famesp.com.br/wpcontent/uploads/2016/10/famesp_denise_yukie_kato.pdf.

Lima, M. (2021). O seu evento online não tem que ser virtual. Website Treinamentos online. https://treinamentosonline.com.br/?gclid=EAIaIQobChMI9fKT8--57gIVggeRCh00MQSZEAAYAiAAEgK12DBwE.

Saraiva, A. (2020). Casamentos reduzem pelo quarto ano seguido e passam a durar menos tempo. Website Agência de notícias. https://agenciadenoticias.ibge.gov.br/agencia-noticias/2012-agencia-de-noticias/noticias/29647-casamentos-reduzem-pelo-quarto-ano-seguido-e-passam-adurar-menos-tempo.

SEBRAE (2020). Entenda o impacto da pandemia no setor de eventos. Website SEBRAE. https://www.sebrae.com.br/sites/PortalSebrae/artigos/entenda-oimpacto-da-pandemia-no-setor-de-eventos,424ba538c1be1710VgnVCM1000004c00210aRCRD.

Silva, R. E. G. da. \& Minciotti, S. A.(2021) . Marketing Público como facilitador do processo de troca na Administração Pública. Research, Society and Development. 10(5), e59610515597, 2021. DOI: 10.33448/rsd-v10i5.15597. https://rsdjournal.org/index.php/rsd/article/view/15597.

TRT (2021). Tribunal Regional do Trabalho $7^{\mathrm{a}}$ Região. Gerenciamento dos riscos do projeto. Website TRT7. https://www.trt7.jus.br/files/institucional/governanca_ti/processos/processo-trt7/index.htm.

Vicente, T. (2021). 5 pilares para uma Gestão de Pessoas: Como gerenciar um time de alta performance. Website Dinâmica consultoria. https://www.dinamicaej.com.br/gestao-de-pessoas/?gclid=EAIaIQobChMI9cGGidHz7gIVmYvICh3vfAbLEAAYBCAAEgKNWfD_BwE.

Wood Junior, T. \& Zuffo, P. K. (1998). Administração da produção e sistemas da informação- supply chain management. RAE- Revista de Administração de Empresas. 8(3). http://dx.doi.org/10.1590/S0034-75901998000300007. 